\title{
CORRIGENDA
}

\section{Durable fear memories require PSD-95}

PJ Fitzgerald, CR Pinard, MC Camp, M Feyder, A Sah, HC Bergstrom, C Graybeal, Y Liu, OM Schlüter, SGN Grant, N Singewald, W Xu and A Holmes

Molecular Psychiatry (2015) 20, 913; doi:10.1038/mp.2015.44; published online 31 March 2015

Correction to: Molecular Psychiatry advance online publication, 16 December 2014; doi:10.1038/mp.2014.161

Following publication of this paper, the authors noticed that the wrong author was listed as the corresponding author. Correspondence should be addressed to:
Dr CR Pinard, 5625 Fishers Lane, Room 2N09, Rockville, MD 20852-9411, USA.

E-mail: Courtney.Pinard@nih.gov

\section{Identification of increased genetic risk scores for schizophrenia in treatment-resistant patients}

J Frank, M Lang, SH Witt, J Strohmaier, D Rujescu, S Cichon, F Degenhardt, MM Nöthen, DA Collier, S Ripke, D Naber and M Rietschel

Molecular Psychiatry (2015) 20, 913; doi:10.1038/mp.2015.52; published online 14 April 2015

Correction to: Molecular Psychiatry (2015) 20, 150-151; doi:10.1038/mp.2014.56; published online 3 June 2014

Following publication of this paper, the authors noticed an error regarding the direction of the association of clozapine response with polygenic score in the second sentence of the second paragraph in the right column. The corrected sentence appears below.

Furthermore, polygenic risk scores were higher in $\mathrm{Cloz}^{+}$nonresponders compared to $\mathrm{Cloz}^{+}$responders $(P=0.06)$. 